\title{
O estudo da forma urbana no Espírito Santo
}

\author{
The study of urban form in Espirito Santo
}

Flavia Ribeiro Botechia[a] (D), Eneida Maria Souza Mendonça[a] (D), Michela Sagrillo Pegoretti[b,c] (D)

\author{
[a] Universidade Federal do Espírito Santo (UFES), Departamento de Arquitetura e Urbanismo, Vitória, ES, Brasil \\ [b] Centro Universitário Faesa, Campus Vitória, Vitória, ES, Brasil \\ [c] Universidade Federal do Espírito Santo (UFES), Campus de Goiabeiras, Vitória, ES, Brasil
}

Como citar: Botechia, F. R., Mendonça, E. M. S., \& Pegoretti, M. S. (2020). 0 estudo da forma urbana no Espírito Santo. urbe. Revista Brasileira de Gestão Urbana, 12, e20190273. https://doi.org/10.1590/2175-3369.012.e20190273

\section{Resumo}

O objetivo deste artigo é contribuir para a periodização do estudo sobre a forma urbana no estado do Espírito Santo, mais especificamente a partir do ponto de vista dos pesquisadores vinculados à Universidade Federal do Espírito Santo (UFES), na qual se sedia, desde 1979, o curso de graduação em Arquitetura e Urbanismo. Na primeira parte do texto, sugere-se a existência de três períodos de ensino e pesquisa em Morfologia Urbana, quais sejam: os primeiros anos, a consolidação com formação de redes e a difusão. Ao final do artigo, relatam-se as experiências mais atuais e as perspectivas futuras que estão alinhavadas com toda a formação precedente.

Palavras-chave: Morfologia. Ensino. Pesquisa. Espírito Santo. UFES.

\begin{abstract}
The aim of this paper is to contribute in the study of periodization on the urban form in Espirito Santo Brazil. More specifically from the point of view of the researchers associated with Architecture and Urbanism department of Federal University of Espirito Santo (UFES), where since 1979 the graduation course of Architecture and is hosted. In the first part of this work it was suggested the existence of three periods of teaching and research in Urban Morphology, namely: the early years, the consolidation with formation of networks and the diffusion. At the end of the paper, it was reported the most current experiences and future perspectives imagined are aligned with all previous formation.
\end{abstract}

Keywords: Morphology. Teaching. Research. Espirito Santo. UFES.

\section{Introdução}

A morfologia urbana vem sendo um campo de interesse crescente nos estudos urbanos, seja no modo analítico, seja no propositivo. 0 que se verifica no âmbito internacional, lusófono e brasileiro é percebido

FRB é arquiteta urbanista, doutora em Arquitetura e Urbanismo, professora, e-mail: flaviabotechia@gmail.com EMSM é arquiteta, doutora em Arquitetura e Urbanismo, professora titular, e-mail: eneidamendonca@gmail.com MSP é Arquiteta urbanista, doutoranda em Geografia, professora, e-mail: michelasagrillo@yahoo.com.br 
também na escala estadual, no Espírito Santo, Sudeste do Brasil. 0 recente crescimento desses estudos no estado, realçado na Conferência da Rede Lusófona de Morfologia Urbana (Portuguese Network of Urban Morphology - PNUM) em 2017, tem antecedentes que este artigo, de modo inédito, busca apresentar após contextualização nacional a seguir.

Durante os anos correspondentes à segunda metade do século XX, na Europa desenvolveram-se os mais importantes estudos morfológicos pelo arquiteto italiano Saverio Muratori e pelo geógrafo M. R. G. Conzen, considerados referências fundamentais nos estudos sobre a forma urbana (Oliveira, 2016; Pereira Costa \& Gimmler, 2015), o primeiro desenvolvendo pesquisas acerca do tipo edificado em cidades italianas, e o segundo, aspectos histórico-geográficos da forma urbana. De modo concomitante, no Brasil realizaram-se, durante a década de 1960, estudos sobre a forma física de cidades históricas, a estrutura urbana da metrópole latino-americana e ainda os tipos edificados a exemplo daqueles publicados pelo Prof. Nestor Goulart Reis, em Contribuição ao estudo da evolução urbana do Brasil: 1500-1720 (Reis, 1968) e em Quadro da arquitetura no Brasil (Reis, 1970). Esses estudos urbanos em distintas escalas, a depender do contexto do objeto de estudo, enfatizam a importância da análise dos elementos urbanos sem se esquecer, no caso brasileiro, da influência teórica francesa, de cunho social e político, tendo como um dos principais expoentes o filósofo Henri Lefebvre. Essa influência, em conjunto com os estudos supracitados, consolidou-se como base teórica nas décadas subsequentes aos anos 1960 no Brasil.

Para entender o cenário brasileiro dessa época, principalmente a realidade e a desigualdade social, uma série de pesquisadores recorreram ao entendimento do fenômeno urbano também a partir de ações de difusão realizando eventos, visando não só ao debate teórico, mas também à formação. Um desses eventos em destaque foi o Seminário sobre Desenho Urbano (Sedur I), em 1984, organizado por jovens professores oriundos de Brasília, São Paulo, Porto Alegre, Minas Gerais e Rio de Janeiro, tendo como nome principal seu mentor o professor Benamy Turkienicz (1984). A essa iniciativa, juntam-se outras como a promoção de cursos de pós-graduação com temáticas voltadas à tipologia e evolução da forma urbana, como aquele com o professor Ivor Samuels, promovido pela Universidade de Birmingham e Oxford Brookes, no Rio de Janeiro (Pereira Costa, 2007).

A realização de eventos, cursos e publicação de textos e livros culminou na realização, em 2007, de uma das edições do International Seminar of Urban Form (ISUF) na cidade de Ouro Preto (Minas Gerais). Esse evento, coordenado pelos professores Juca Vilaschi e Stael de Alvarenga Pereira Costa, da Escola de Arquitetura da Universidade Federal de Minas Gerais, foi a primeira edição fora da Europa e dos Estados Unidos. Com 412 abstracts submetidos, os números dessa edição em Ouro Preto foram considerados recordes, como registrou Jeremy Whitehand em ISUF 2007 Conference Report (Whitehand, 2008). De uma participação brasileira que girava em torno de, no máximo, cinco artigos nas edições anteriores, em 2007, dos cerca de 220 artigos selecionados, aproximadamente 150 foram de autoria de pesquisadores brasileiros, correspondente a $66 \%$ do total. Esse fato destacou, por um lado, o interesse pela temática, mas, por outro, registrou os desafios da discussão sobre a forma urbana.

Se foi possível a identificação, por parte dos autores supracitados, de landmarks nacionais no que concerne aos estudos sobre a forma urbana, há de se reconhecer a existência de lacunas relativas à produção teórica de cunho regional que, entretanto, podem ser preenchidas. A vasta dimensão continental do Brasil requer um olhar sobre as especificidades locais potencializando o registro e a difusão dos esforços imbuídos nesse contexto.

A partir do breve panorama nacional exposto nesta introdução, visto já ter sido amplamente tratado em outras publicações (Pereira Costa, 2007; Pereira Costa \& Teixeira, 2014; Pereira Costa \& Gimmler, 2015; Botechia, 2017), o objetivo deste artigo é contribuir para a periodização do estudo sobre a forma urbana no estado do Espírito Santo, mais especificamente a partir do ponto de vista dos pesquisadores vinculados à Universidade Federal do Espírito Santo (UFES), na qual se sedia, desde 1979, o curso de graduação em Arquitetura e Urbanismo, o mais antigo do estado. Sugere-se, conforme apresentado a seguir, a existência de pelo menos três períodos de ensino e pesquisa em Morfologia Urbana, quais sejam: os primeiros anos, a consolidação com formação de redes e a difusão. Ao final do artigo, relatam-se as 
experiências mais atuais e as perspectivas futuras que estejam alinhavadas com toda a formação precedente.

\section{O ensino e a pesquisa em Morfologia Urbana no Espírito Santo}

\section{Os primeiros anos do curso de Arquitetura e Urbanismo na Universidade Federal: de 1979 a 1995}

Diante da retrospectiva nacional antes apresentada, reconhecem-se diversas influências daí advindas nos estudos sobre a forma urbana no Espírito Santo. Considerando a área de Planejamento Urbano, como o ponto de vista das autoras deste artigo, nota-se que os primeiros professores dessa área, no curso de Arquitetura e Urbanismo da Universidade Federal do Espírito Santo, articulavam-se à vertente crítica de reflexão sobre o "direito à cidade", sendo uma vertente reflexiva importante no período de ditadura militar no Brasil e ainda hoje, como indicado por Pereira Costa \& Teixeira (2014).

No ano de 1982, foi seminal a publicação O colégio e as residências jesuítas no Espírito Santo, de José Antônio Carvalho, professor do Centro de Artes da Universidade Federal do Espírito Santo, pelo pioneirismo no registro documental e estudo tipológico das igrejas, legado da presença dessa ordem religiosa em terras capixabas e recentemente publicada em uma segunda edição (Carvalho, 2019). Ao longo do período, foram diversas as iniciativas de Maria Izabel Perini Muniz no estudo sobre a arquitetura da imigração no Espírito Santo, incluindo o registro de residências, fazendas e igrejas de origem italiana e alemã. Trata-se de trabalhos relevantes considerando o pioneirismo dos registros, tendo em vista o fato de os jesuítas terem tido papel significativo na ocupação do território capixaba entre os séculos XVI e XVIII, do mesmo modo que os imigrantes europeus, sobretudo italianos, no século XIX (Muniz, 1990).

Na segunda metade da década de 1980, o curso de Arquitetura e Urbanismo deu os primeiros passos no campo da pesquisa de modo sistemático, sendo possível nominar o estudo de Sarah Santos sobre habitação social na Grande Vitória, abordando a política habitacional, o parcelamento do solo, os modelos construtivos e a respectiva implantação, como a primeira pesquisa sobre o tema, estabelecendo vínculos entre forma urbana e questões políticas e sociais (Santos et al., 1993). Vitória, além de capital, era o núcleo de uma aglomeração urbana, conurbada com quatro outros municípios vizinhos, que, entre 1955 e 1985, passaram por intenso processo de urbanização.

Esse período é caracterizado por Rocha \& Morandi (1991) como um período de transição econômica no Espírito Santo, da agroexportação cafeeira para a grande indústria siderúrgica. Segundo esses autores, a política de erradicação de cafezais, instituída no Brasil nas décadas de 1950 e 1960, atingiu, de modo mais acentuado, o Espírito Santo que outros estados, desestruturando a base agrícola (econômica e social) existente e estimulando a migração para a capital. Esse processo migratório se fortaleceu ainda nas décadas de 1970 e 1980 pela industrialização, que, a partir do Plano Nacional de Desenvolvimento (PND) (Brasil, 1974), promoveu a execução de grandes projetos como portos e indústrias siderúrgicas e de celulose em Vitória e nas proximidades. Nesse contexto, houve uma elevação acentuada de população na Grande Vitória, de mão de obra qualificada e também não qualificada para os postos de trabalho existentes, resultando na ocupação de áreas com habitação precária, tornando especialmente relevante o estudo sobre políticas públicas e habitação, anteriormente mencionado.

Também na segunda metade dos anos 1980, os professores Eneida Mendonça e José Francisco Bernardino Freitas, ao ingressarem no corpo docente da universidade, adicionaram, àquelas preocupações, as referências do professor Nestor Goulart Reis com a histórica articulação entre lote e arquitetura nas cidades brasileiras e, principalmente, de Carlos Nelson Ferreira dos Santos, que, como arquiteto e antropólogo, deu destaque à rua na vida urbana em Quando a rua vira casa (Santos, 1981) e ao jogo político associado ao projeto de cidades em A cidade como um jogo de cartas (Santos, 1988). 
Foi e ainda se faz importante a publicação de Del Rio, Introdução ao desenho urbano no processo de planejamento, que, sob o subtítulo de Morfologia urbana, como uma das categorias de análise e projeto recomendadas, trata do tema em suas diversas escalas, sempre associando a abordagem analítica à projetual (Del Rio, 1990).

Já na década de 1990, José Francisco Bernardino Freitas, em doutorado na London University, trouxe a influência de Peter Hall, em Cidades do Amanhã (Hall, 1988), e Eneida Mendonça, em mestrado na Universidade de São Paulo (Mendonça, 1999), aproximou-se do estudo do professor Silvio Soares Macedo sobre a evolução urbana do bairro Higienópolis (Macedo, 1987), desenhada e analisada em quadra, lotes, ocupação e arquitetura, de Philippe Panerai (Panerai et al., 1986), em a Análise da forma urbana, e Carlo Aymonino (1984), em O significado das cidades. Desse processo, pode-se dizer que resultou a dissertação de mestrado de Mendonça (1996), na qual trata da evolução de ocupação urbana de dois territórios reconhecidos em Vitória (Camburi e Goiabeiras) e do método trabalhado em aulas por Freitas sobre parcelamento do solo e estudos sobre densidade urbana.

\section{Os anos de formação de redes: de 1995 a 2016}

A partir dos anos 1990, pesquisadores do curso de Arquitetura e Urbanismo da Universidade Federal do Espírito Santo passaram a se dedicar à criação dos núcleos de estudos, associando-se, ou não, às redes nacionais, com objetivo de dar ênfase às práticas de pesquisa e extensão, tendo sido esse o período de doutoramento de grande parte desses professores.

Em 1995, do ponto de vista das pesquisas com ênfase na história da cidade e do urbanismo e planejamento urbano, os professores Eneida Maria Souza Mendonça, José Francisco Bernardino Freitas, Martha Machado Campos e Renata Hermanny de Almeida institucionalizaram o Núcleo de Estudos de Arquitetura e Urbanismo (NAU), tendo produzido, em pesquisas individuais, coletivas ou orientações de graduandos, diversos papers, livros e artigos, entre os quais se destaca a publicação do livro Cidade Prospectiva: o projeto de Saturnino de Brito (Mendonça et al., 2009). Mesmo publicado posteriormente, o livro refere-se à pesquisa e à exposição realizada por aqueles pesquisadores em 1996, no centenário do projeto de Brito para Vitória.

Embora sem conotação explicitamente relacionada ao campo da Morfologia Urbana, a produção acadêmica desse período foi imprescindível para a compreensão dos processos de produção da forma urbana ao incidir sobre a investigação das bases de engenheiros e arquitetos que atuaram em planos urbanísticos, levantamentos arquitetônicos patrimoniais e na recolha de dados primários acerca da formação de bairros da Região Metropolitana da Grande Vitória.

Deste modo, os estudos sobre o projeto de Brito e o doutoramento de Mendonça na USP aproximaram, ainda em 1996, esse grupo de professores da rede de pesquisa Urbanismo no Brasil, do qual fazem parte, ainda hoje, Mendonça e Freitas. Essa rede, coordenada pela professora Maria Cristina da Silva Leme, da Universidade de São Paulo, envolve pesquisadores de nove universidades brasileiras (USP, UPM, UFF, UFES, UFRGS, UFJF, UFBA, UFPE e UNB), com o propósito de realizar levantamento e análise de documentação sobre o Urbanismo e o Planejamento Urbano no Brasil, tratando do tema de cidades específicas (São Paulo, Niterói, Rio de Janeiro, Vitória, Porto Alegre, Belo Horizonte, Salvador, Recife e Brasília), de modo correlacionado e comparativo entre elas, mas também de modo mais geral, no contexto brasileiro e latino-americano.

Mesmo que o enfoque da rede seja a História do Urbanismo e do Planejamento Urbano, os levantamentos documentais de projetos, plantas, relatórios, legislação urbanística e biografias de urbanistas realizados tornaram-se, posteriormente, base para estudos avançados no campo da Morfologia Urbana. Em 1999, como primeiro produto dessa rede, publicou-se o livro Urbanismo no Brasil 1895-1965 (Leme, 1999), com guia de fontes e artigos. 0 guia de fontes foi publicado de modo ampliado posteriormente, em CD-ROM (Leme, 1999), e, em 2001, também no website (www.urbanismobr.org), contendo título, breve descrição, endereço dos acervos e registros iconográficos de apenas alguns 
documentos, considerando dificuldades da tecnologia disponível à época para uma abrangência maior. Entre os artigos, Mendonça (1999 in: Leme, 1999) analisa traçados urbanísticos de três projetos para bairros de Vitória (Novo Arrabalde, Camburi e Villa Balneária de Camburi), com destaque à superposição de diagonais sobre a malha regular, aos moldes de L'Enfant, Cerdá e Aarão Reis, respectivamente, em Washington, Barcelona e Belo Horizonte. Em publicações seguintes dessa rede, tiveram continuidade os estudos sobre portos, aterros e verticalização de construções em Vitória, de modo comparativo com o de outras cidades como Porto Alegre e Niterói (Freitas, 2010), bem como estudos sobre o Urbanismo no Brasil em períodos de exceção, entre os quais, envolvendo Vitória, há os estudos de Mendonça (Rezende, 2012; Leme, 2019) sobre o projeto do engenheiro Henrique de Novaes no período denominado Era Vargas, entre 1930 e 1945, e sobre a estruturação portuária, política habitacional e expansão urbana, na década de 1960.

Em 2001, Mendonça concluiu o doutorado estudando o percurso da verticalização de construções em Vitória, registrando as alterações tipológicas dos edifícios altos ao longo do tempo (Mendonça, 2001). Em 2006, a partir de novas pesquisas envolvendo a análise e a construção da paisagem e a apropriação de espaços públicos em Vitória, ocorreu a integração dessa pesquisadora à Rede de Pesquisa do Quadro do Paisagismo no Brasil - Sistemas de Espaços Livres (QUAPÁ-SEL), constituída pelo Laboratório Quadro do Paisagismo no Brasil (QUAPÁ), e coordenada pelos professores Sílvio Macedo e Eugenio Queiroga, da Faculdade de Arquitetura e Urbanismo da Universidade de São Paulo.

Essa rede conta com dezenas de universidades e pesquisadores, tratando de dezenas de cidades brasileiras em todas as regiões do Brasil, atendendo, inicialmente, ao propósito de identificar, classificar e analisar as especificidades e generalidades sobre o Sistema de Espaços Livres (SEL) e a esfera pública no país. Para essa finalidade, a metodologia da coordenação nacional realizada pelo Laboratório QUAPÁ incluía a formação de núcleos em cada cidade/universidade associada à rede, sendo o Núcleo Vitória, do NAU, desde então, coordenado por Mendonça, o responsável pelos estudos sobre Vitória e municípios vizinhos, alcançando os primeiros resultados em 2007 (Campos et al., 2012).

Pode-se inferir que a aproximação da Rede QUAPÁ-SEL aos estudos da forma urbana, lançando, em 2011, a pesquisa sobre Sistema de Espaços Livres e forma urbana no Brasil (Macedo et al., 2018), tenha ocorrido pelos estudos iniciais de seu coordenador, Sílvio Macedo, sobre Higienópolis, na década de 1980. No entanto, a aproximação dessa rede a redes internacionais como ISUF e PNUM teve, sem dúvida, forte estímulo de Staël Pereira Costa, participante dessas três redes e coordenadora, na Rede QUAPÁ-SEL, do Núcleo Belo Horizonte. Como já indicado, Pereira Costa coordenou o ISUF Ouro Preto em 2007, no qual pesquisadores da Rede QUAPÁ-SEL estiveram presentes, e faz parte do Conselho Científico do PNUM, desde a sua criação, sendo atualmente sua vice-presidente.

A rede PNUM, criada por pesquisadores portugueses no ISUF de 2010, contou, desde o ano inicial de existência, com o interesse de pesquisadores brasileiros, panorama crescente, sobretudo a partir de 2012, com a realização de sua segunda conferência anual, em Lisboa. A partir de então, entre outros brasileiros, os pesquisadores da Rede QUAPÁ-SEL e do NAU-UFES participam intensivamente das conferências PNUM.

Essa intensa participação brasileira estimulou a decisão da rede PNUM em 2014 a realizar suas conferências alternadamente, no Brasil e em Portugal, sendo a de 2015 realizada na UNB, com coordenação de Frederico Holanda, e a 2016 na Universidade do Minho, em Guimarães, com a coordenação de Jorge Correia, ocasião em que se oficializou a realização da $6^{\underline{a}}$ Conferência na Universidade Federal do Espírito Santo, em Vitória, coordenada por Eneida Mendonça e Milton Esteves Junior.

Assim, o estreito contato com esta rede lusófona, o PNUM, que atua desde 2010 concatenando os interesses de cerca de 15 países de língua portuguesa e campos disciplinares como Arquitetura e Urbanismo, Planejamento Urbano, Engenharia, Geografia e História, abriu novas e renovadas possibilidades de pesquisa, em Vitória, na UFES e no Espírito Santo, como será visto a seguir. A preparação e a organização da 6 ${ }^{a}$ Conferência da Rede Lusófona de Morfologia Urbana em Vitória ocorreram em período em que os Programas de Pós-Graduação em Arquitetura e Urbanismo e em 
Geografia da UFES, instituídos, respectivamente, em 2007 e 2008, estavam consolidados e capacitados à cooperação acadêmica com instituições de ensino portuguesas, marcando a inserção da Universidade Federal do Espírito Santo no contexto da morfologia urbana lusófona, em caráter internacional.

\section{O fortalecimento da pesquisa local e a difusão internacional: de 2016 a 2019}

O contexto precedente levou a um novo landmark no ano de 2017, a realização da 6므 Conferência da Rede Lusófona de Morfologia Urbana, PNUM 2017, na capital do Espírito Santo entre os dias 24 e 25 de agosto de 2017, coordenada pelos professores Eneida Mendonça e Milton Esteves Junior e pelos Programas de Pós-Graduação em Arquitetura e Urbanismo e em Geografia da Universidade Federal do Espírito Santo. 0 tema principal desse evento, Morfologia Urbana: Território, Paisagem e Planejamento, tratou das possibilidades e dos alcances do estudo da forma urbana na configuração e no planejamento/projeto do território e da paisagem. Intrínsecos à problemática estiveram presentes a articulação e os limites entre manutenção da memória coletiva e desejo de transformação e a construção de estratégias que assegurassem a justiça socioespacial.

Previamente à realização do evento, com o propósito de difundir o tema da $6^{\underline{a}}$ Conferência no meio acadêmico local, dois eventos foram organizados e realizados, ainda em 2016. 0 primeiro refere-se ao Seminário Acervo documental de planejamento: o desafio de sua conservação e a potencialidade para compreensão da cidade. 0 seminário, realizado na UFES, teve o propósito de divulgar a exposição virtual do Escritório do Plano de Urbanismo da Cidade de Salvador, tendo sido também a oportunidade de conhecer os estudos de Flávia Ribeiro Botechia sobre o Atlas Urbanístico de Vitória, bem como de Heraldo Ferreira Borges sobre exame da cartografia e compreensão da cidade de Lisboa, além dos principais acervos cartográficos de Vitória, apresentados pelos técnicos por eles responsáveis. No entanto, o segundo evento é o que forneceu impulso definitivo ao estudo do tema no Espírito Santo. Trata-se do workshop Morfologia urbana: forma urbana em áreas conquistadas ao mar, que propiciou aprofundamento de estudos acerca da forma urbana da cidade de Vitória, gerando base para a formulação de uma publicação científica, atualmente no prelo (Figura 1).

Esse workshop foi organizado pela professora Eneida Mendonça em conjunto com os arquitetos urbanistas Heraldo Borges, que vinha de formação de mestrado em Lisboa, e Flávia Ribeiro Botechia ambos, então, doutorandos na Universidade Presbiteriana Mackenzie, em São Paulo, desenvolvendo teses com temática voltada aos estudos da forma urbana. Realizado entre 2 e 6 de setembro de 2016 na Universidade Federal do Espírito Santo, o evento reuniu 21 participantes entre professores e estudantes de graduação e pós-graduação não só da UFES, mas também do Instituto Federal do Espírito Santo, campus Colatina, e de demais centros universitários locais da rede particular de ensino.

Esse evento foi formatado em três momentos distintos. O primeiro deles foi destinado ao conhecimento das quatro abordagens morfológicas que refletem as principais correntes nos estudos da forma urbana, a saber: histórico-geográfica, processual tipológica, configuracional e espacial analítica (Kropf, 2009). Na oportunidade, os coordenadores apresentaram as referidas abordagens, tendo como convidado, via teleconferência, o pesquisador e professor Vítor Oliveira, da Universidade do Porto e Universidade Lusófona do Porto, que proferiu aula introdutória. 0 segundo momento enfocou a pesquisa de campo, e o último, a análise dos dados obtidos, após aplicação dos conceitos metodológicos apreendidos. 0 objeto de estudo dos participantes foram dois eixos perpendiculares à linha da costa localizados nos bairros Centro e Praia do Suá, em Vitória, enfocando a análise em duas abordagens: histórico-geográfica e processual tipológica.

Os participantes do evento foram divididos em quatro grupos, ficando cada grupo encarregado da análise do trecho por meio de uma das abordagens morfológicas. Em seguida, o Workshop tomou formato de oficina, em que cada grupo, a partir dos dados coletados, confeccionou esquemas gráficos, mapas e diagramações que foram analisados, discutidos, orientados pelos coordenadores e apresentados no último dia do evento, o que culminou em reflexões a partir dos resultados alcançados e das características 
das abordagens estudadas, tendo como finalidade o apontamento de potencialidades e fragilidades de cada uma das abordagens e uma desejada utilização integrada. Esses estudos foram acompanhados por meio de comunicação via correio eletrônico entre alunos e professores, após a oficina, com correções e recomendações, resultando em aperfeiçoamento do texto a ser publicado.

0 desdobramento das atividades desse evento para a difusão do interesse pelo estudo da forma urbana no Espírito Santo foi amplo e diversificado, estando ainda a repercutir. No ano seguinte, três dos grupos submeteram seus respectivos resultados em forma de artigo ao PNUM 2017, deixando claro que o Workshop começara a difundir abordagens das duas principais escolas de morfologia urbana no estado do Espírito Santo. Além disso, duas alunas do workshop desenvolveram projetos de pesquisa, a partir dos ensinamentos obtidos, alcançando aprovação na seleção para mestrado e doutorado em Geografia na UFES. E, por fim, observou-se ainda que a presença de professores no workshop favoreceu, logo em seguida, a orientação de trabalhos acadêmicos de final de curso, sobre o tema da forma urbana, tendo sido responsável ainda pela intensa presença de seus jovens alunos no PNUM 2017 em Vitória.

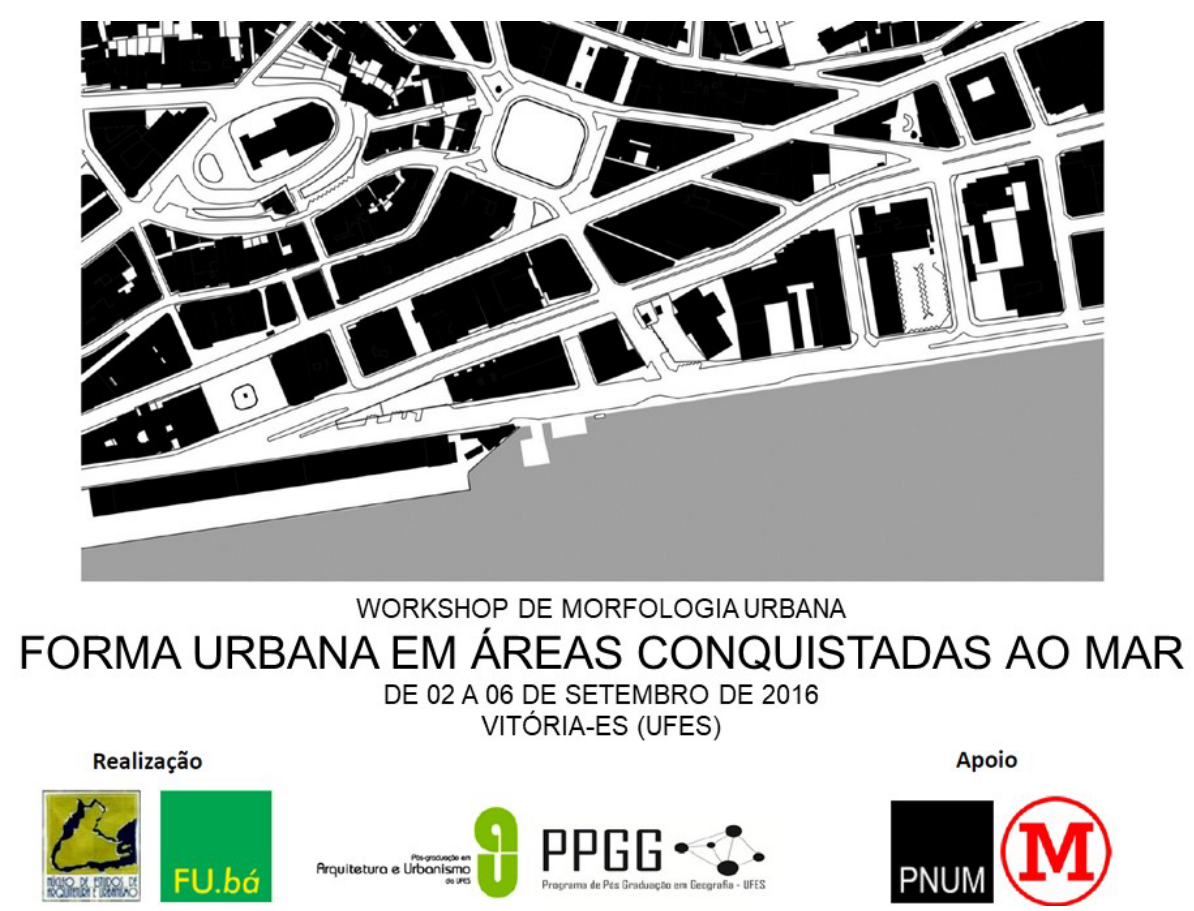

Figura 1 - Registro da chamada para o workshop em Morfologia Urbana, realizado em 2016 como atividade pré-PNUM. Fonte: Autores (2016).

Buscando então alcançar os objetivos pretendidos, o PNUM 2017 foi estruturado em sete eixos temáticos, alguns acompanhando a tradição conceitual e prática das conferências antecedentes, e outros bem voltados para articulações da forma urbana com aspectos sociais do Brasil contemporâneo, tais como (Rede Lusófona de Morfologia Urbana, 2017, p. 7):

1. Regimes de interação com a forma urbana: metodologias de abordagem; procedimentos analíticos; metanarrativas descritivas; 2 . Configuração, forma e reforma urbanas: aproximações epistemológicas; estratégias projetuais; devir urbano; 3. História urbana e patrimônio material/imaterial: legados; permanências; transformações; 4. Configuração territorial e urbana: escalas de abrangência; modelos de desenvolvimento; local versus global; 5. Sistemas urbanos e condição suburbana: cidade formal, assentamentos aformais; ocupações ilegais; 6. Padrões morfológicos e sistemas de espaços livres urbanos: modos de apropriação; instrumentos legais; atores e agentes envolvidos; 7. Ambiente construído e sustentabilidade: inquietações projetuais; métodos construtivos; interações tecnológicas. 
Esses eixos temáticos orientaram a submissão de 331 trabalhos, dos quais 243 foram aprovados, sendo 147 integrantes da programação dos dois dias de atividades, para apresentação e debate em sessões paralelas. Dos trabalhos apresentados e que estão vinculados a muitas instituições de ensino públicas e particulares do Brasil, além daqueles de origem internacional, 16 são resultantes de estudos vinculados às instituições do estado, o que equivale a aproximadamente $11 \%$ do total. Tal fato vem demonstrar envolvimento em pesquisas por parte da comunidade acadêmica capixaba em eventos científicos, o que pode ser fruto de uma geração de alunos formados pela UFES e que vem despertando interesse pela iniciação científica e pós-graduação no campo da morfologia urbana.

Vale ressaltar que a Comissão Organizadora e a Equipe de Apoio do PNUM 2017 foram constituídas, em sua maioria, por participantes do Workshop de Morfologia Urbana realizado no ano anterior, e os coordenadores do referido evento compuseram, em conjunto com outros professores brasileiros e portugueses, o Comitê Científico do PNUM 2017 (Figura 2). Tal fato mostra o envolvimento desse grupo não só com a temática da morfologia urbana em eventos científicos, mas também em estudos publicados, finalizados e iniciados posteriormente, em 2018 e 2019.

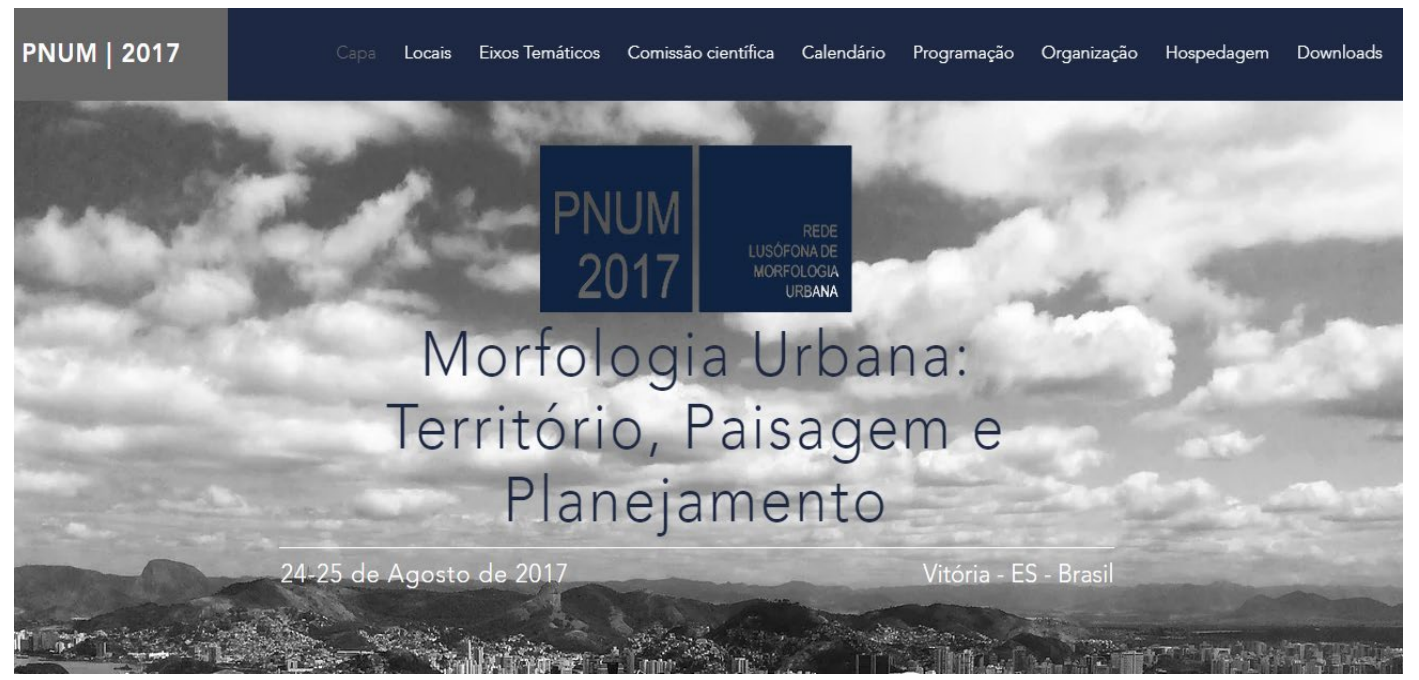

Figura 2 - Capa do website criado para a realização da Conferência PNUM 2017 com o tema Morfologia Urbana: território, paisagem e planejamento. Foto de fundo: Giovani Goltara. Fonte: Autores (2017).

Associado à referida conferência, organizou-se e propôs-se como pós-evento o $1^{\mathrm{o}}$ Curso de Morfologia Urbana no estado, que teve a participação de pesquisadores portugueses, propiciando ampliação de troca de conhecimento entre os grupos de pesquisa das universidades envolvidas. Assim, Vítor Oliveira (Universidade do Porto), Jorge Correia (Universidade do Minho), a recém-doutora Flávia Botechia e a professora Eneida Mendonça ministraram o curso com aulas teóricas, trabalhos orientados e visitas a campo não só em Vitória, mas também em Serra, município componente da Região Metropolitana da Grande Vitória.

O curso contou com cerca de 30 participantes, sendo composto essencialmente dos que haviam realizado o Workshop de Morfologia no ano anterior, além de outros estudantes, professores e profissionais. A temática desenvolvida retomou o estudo das quatro abordagens da forma urbana e seus elementos, além de outros relacionados aos atores e processos de transformação urbana, patrimônio urbano de influência portuguesa no universo islâmico, estudos morfológicos aplicados e estudo de sistemas de espaços livres em Vitória.

Visando à continuidade do aprendizado na temática da morfologia urbana e fundamentando-se em outras possibilidades de análise, Eneida Mendonça organizou no ano seguinte, em 2018, o 2o Curso de Morfologia Urbana na Universidade Federal do Espírito Santo, intitulado Modelagem urbana computacional, desigualdades e crescimento urbano, ministrado pelo professor Maurício Couto Polidori, pesquisador e professor da Universidade Federal de Pelotas, Rio Grande do Sul.

0 curso foi realizado em três dias e contou, como o anterior, com cerca de 30 participantes entre estudantes, professores e profissionais, em especial aqueles que já haviam participado do Workshop 2016 
e do 1 o Curso de Morfologia 2017, constituindo, assim, continuidade e formação de um grupo articulado e envolvido em âmbito local. A exemplo do workshop realizado em 2016, verificaram-se, no mesmo ano de 2018, repercussões dos ensinamentos de Polidori em trabalhos de graduação orientados por professores que frequentaram o curso, entre outras formas de difusão, indicando o promissor alcance da morfologia urbana no Espírito Santo.

\section{Perspectivas presentes e futuras}

Como desdobramentos, quer sejam vinculados ao grupo de estudos formado e coordenado por Eneida Mendonça, quer sejam a pesquisadores individuais, pode-se dar destaque a algumas iniciativas locais.

Desde o ano de 2014, os pesquisadores Flavia Botechia e Heraldo Borges (Botechia \& Borges, 2014) criaram a pesquisa Atlas Urbanístico de Vitória, já mencionada, que tem como objetivo principal a elaboração de um banco de dados sobre os planos urbanísticos elaborados, durante o século XX, para a cidade de Vitória, encontrando-se na intersecção dos campos teóricos de Arquitetura, Urbanismo, Morfologia Urbana, Arquivologia, Memória, Patrimônio e Tecnologias da Informação. Trata-se de um estudo de constituição, preservação e valorização das bases cartográficas sem as quais os estudos sobre a forma urbana ficam expressamente comprometidos (Figura 3).

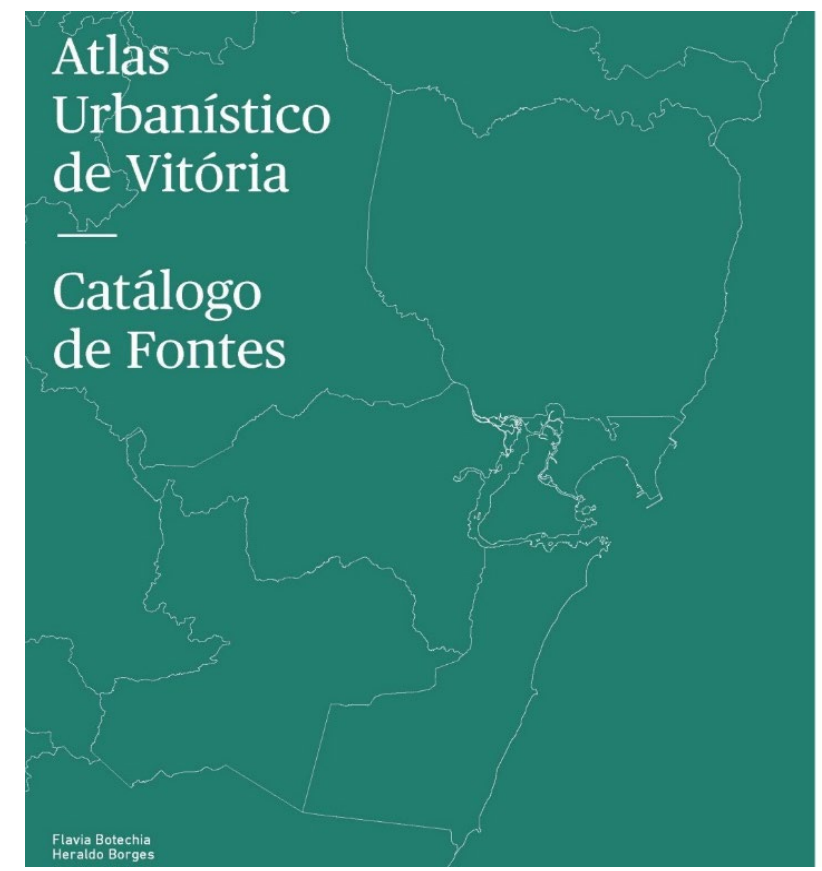

Figura 3 - Capa da publicação Atlas urbanístico de Vitória. Fonte: Botechia \& Borges (2014).

Nesse processo inicial de pesquisa, intitulado Catálogo de Fontes, em instituições custodiadoras locais, identificaram-se cerca de 400 documentos cartográficos e bibliográficos relativos a 13 planos urbanísticos realizados para a cidade de Vitória e consolidou-se uma periodização subdividida em três períodos, que podem ser descritos de acordo com a temática central dos planos e a técnica empregada como propõe Leme (1999): saneamento e melhoramentos da área central (1896-1947), expansão territorial (1947-1973) e legislação urbanística (1973-atual). A análise documental foi tratada por meio de contextualização e descrição dos planos urbanos em relação à data, autor, escala, conteúdo, abrangência territorial, dimensão, suporte e período administrativo, não havendo uniformidade de apresentação desses documentos, uma vez que alguns se encontram na forma de mapas, outros descritos apenas em mensagens de governo ou livros. 
Como desdobramento dessa fase, pode-se afirmar que parte do patrimônio urbanístico local, além de pouco conhecido, encontra-se em vias de desaparecimento. 0 que se observa, de modo geral, são documentos incompletos e danificados ao longo do tempo, além de estarem hoje alocados em diferentes lugares, dificultando tanto acesso quanto sua interpretação. Apesar de tudo, a importância do estudo das cartografias se confirmou e reafirmou, pois há no material encontrado, a despeito de todos os problemas, registros preciosos de diferentes etapas de metamorfose e planejamento da cidade. Por esse motivo, o Catálogo de Fontes desdobra-se nesse ano de 2019 na imprescindível fase seguinte de digitalização e publicização do acervo, o que constitui a etapa do projeto Atlas Urbanístico: Plataforma Digital Interativa, aprovado no Edital Secult/Funcultura no 14/2018 - Seleção de projetos culturais e concessão de prêmio para inventário, conservação e reprodução de acervos no estado do Espírito Santo e em vias de publicação.

No contexto acadêmico local, reforça-se a pesquisa continuada com publicação de artigos de autoria de alunos orientados pela professora Eneida Mendonça em eventos nacionais e internacionais como QUAPÁ 2018, PNUM 2019 e SIMPURB 2019, este último um Simpósio Nacional de Geografia Urbana. No contexto da pós-graduação, encontram-se em desenvolvimento pesquisas em diferentes níveis, tais como iniciação científica, graduação, mestrado e doutorado, com destaque para a dissertação de mestrado concluída e a tese de doutorado em andamento, ambas vinculadas ao Programa de PósGraduação em Geografia da UFES, das arquitetas Claudia Mello e Michela Sagrillo Pegoretti, respectivamente, que tratam da forma urbana, permanências, apagamentos e transformações na Prainha, em Vila Velha, onde se deu o início da colonização portuguesa no Espírito Santo, e da forma urbana e apropriação em praças de Vitória.

Além da universidade, a difusão das iniciativas de workshop, cursos e eventos anteriormente relatados gerou orientações de trabalhos finais de graduação no Instituto Federal do Espírito Santo, campus Colatina, a partir da formação e capacitação de professoras dessa instituição. Também foi marcante no período mais recente a conclusão das teses de doutoramento, ambas defendidas na Universidade Presbiteriana Mackenzie, em São Paulo, dos pesquisadores em morfologia urbana Flavia Botechia (2017) e Heraldo Borges (2018). Cada um com referencial teórico específico, tiveram como objeto empírico de verificação das hipóteses trechos do território da Região Metropolitana da Grande Vitória.

A pesquisa de Flavia Botechia desenrolou-se com a publicação de um livro cuja seleção se deu por meio do Edital de publicação de obras inéditas de autores capixabas - Secult/Funcultura/Governo do Estado Espírito Santo -, tornando-se um meio de difusão das pesquisas morfológicas (Botechia, 2018). A recente contratação de Flávia Botechia como professora efetiva da UFES contribui para fortalecer os estudos sobre a forma urbana nessa universidade.

Deste modo, a equipe da UFES se amplia, orientando-se à programação, em 2020, de curso e workshop, dando continuidade ao movimento que até então tem contribuído para aprofundar e ampliar o conhecimento sobre a forma urbana e a potencialidade desse estudo para o alcance social almejado para a vida urbana.

\section{Considerações finais}

Diante do exposto e do que pôde ser pesquisado neste intermédio temporal, inferiu-se que os estudos sobre a forma urbana no Espírito Santo acompanharam a evolução dos estudos sobre o tema no contexto nacional apresentado por Pereira Costa \& Teixeira (2014). Assim, identificaram-se expoentes e produtos a partir da realidade local, de forma sistemática, desde os anos iniciais de formação do Centro de Artes da Universidade Federal do Espírito Santo até a contemporaneidade.

Uma questão que alinha o Espírito Santo com o contexto nacional é aquela que coloca a produção acadêmica local vinculada quase que em sua totalidade com a UFES, lócus do ensino e da pesquisa regional. Embora a sede da universidade esteja situada na capital, a produção de conhecimento não se restringiu à cidade Vitória ou às imediações; pelo contrário, conseguiu abarcar o estudo urbano de 
diversos municípios do estado. A construção do conhecimento sobre a Morfologia Urbana acompanhou a criação do curso de Arquitetura e Urbanismo e a formação de seus professores como pesquisadores e doutores, além da busca pela inserção deles em redes de pesquisas nacionais e internacionais.

Outra questão que aparece em destaque se refere ao conteúdo da abordagem teórica predominante. No Espírito Santo, como em outras partes do Brasil, a ênfase política e social encontra-se na base dos estudos urbanos. A mesma orientação pode ser percebida no âmbito morfológico desses estudos, não sendo possível dissociar tal abordagem da tratativa dos aspectos métricos, agentes e processos, nas diferentes escalas de análise, seja no nível do edificado, seja no patamar metropolitano.

Reconhece-se o importante papel desempenhado pela Conferência PNUM 2017, que conferiu alcance nacional e internacional aos trabalhos sobre Morfologia Urbana no Espírito Santo. Sem dúvida também se deve citar os cursos e workshops que antecederam ou sucederam o evento como força investigativa propulsora e aglutinadora com função de despertar, inserir e propagar o interesse de estudiosos em diferentes estágios de conhecimento, sobre as possibilidades desse tema na compreensão e no planejamento do território.

O ensino se constrói com o tempo, e a realidade se altera em tempo ainda maior. Desde os primórdios do curso de Arquitetura e Urbanismo na UFES, há 40 anos, professores movidos por ideais de justiça social valiam-se de conhecimentos que, de algum modo, envolviam a forma urbana, na expectativa de formar gerações de profissionais comprometidos com uma cidade melhor para todos. Passados tantos anos, é especialmente gratificante atuar ao lado desses profissionais, agora professores e pesquisadores, porém ainda na expectativa de alcançar os mesmos ideais. Há muito o que fazer!

\section{Referências}

Aymonino, C. (1984). O significado das cidades. Lisboa: Editorial Presença.

Borges, H. F. (2018). A forma do informe: uma interpretação da morfogênese do território metropolitano da Grande Vitória a partir dos padrões e processos de antropização (Tese de doutorado). São Paulo: Universidade Presbiteriana Mackenzie.

Botechia, F. R. (2017). A forma indelével: estudos morfológicos sobre a persistência elementar em Maruípe, Vitória (Tese de doutorado). Universidade Presbiteriana Mackenzie, São Paulo.

Botechia, F. R. (2018). A forma indelével: um estudo sobre a persistência morfológica em Maruípe. Vitória: SecultFuncultura.

Botechia, F. R., \& Borges, H. F. (2014). Projeto Atlas Urbanístico de Vitória: inventário dos planos urbanos para a cidade de Vitória (ES) ao longo do século XX. In Anais do Encontro Nacional da Associação Nacional de Pesquisa e Pós-graduação em Arquitetura e Urbanismo. São Paulo: Universidade Presbiteriana Mackenzie.

Brasil. (1974). Plano Nacional de Desenvolvimento (pp. 1975-1979). Brasília: Imprensa Oficial.

Campos, A. C. A., Queiroga, E. F., Galender, F. C., Degreas, H. N., Akamine, R., Macedo, S. S., \& Custodio, V. (2012). Quadro dos sistemas de espaços livres nas cidades brasileiras. São Paulo: FAUUSP.

Carvalho, J. A. (2019). O colégio e as residências dos jesuítas no Espírito Santo (2. ed.). Vitória: Edufes.

Del Rio, V. (1990). Introdução ao desenho urbano no processo de planejamento. São Paulo: Pini.

Freitas, J. F. B. (2010). Diálogos: urbanismo BR. Vitória: EDUFES.

Hall, P. (1988). Cidades do amanhã. São Paulo: Perspectiva.

Kropf, K. (2009). Aspects on urban form. Urban Morphology, 13, 105-120.

Leme, M. C. S. (1999). Urbanismo no Brasil (1895-1965). São Paulo: Nobel; FUPAM.

Leme, M. C. S. (2019). Urbanismo e política no Brasil dos anos 1960. São Paulo: Annablume. 
Macedo, S. S. (1987). Higienópolis e arredores: processo de mutação da paisagem urbana. São Paulo: Faculdade de Arquitetura e Urbanismo, Universidade de São Paulo.

Macedo, S. S., Queiroga, E. F., Campos, A. C. E., \& Custodio, V. (2018). Quadro geral da forma e do sistema de espaços livres das cidades brasileiras (Vol. 2). São Paulo: Faculdade de Arquitetura e Urbanismo da Universidade de São Paulo.

Mendonça, E. M. S. (1996). (Trans)formação planejada de territórios urbanos em Vitória (ES): o bairro Camburi (Dissertação de mestrado). Universidade de São Paulo, São Paulo.

Mendonça, E. M. S. (1999). O traçado de novos bairros em Vitória: repercussões do projeto de um novo arrabalde. In M. C. S. Leme (Ed.), Urbanismo no Brasil (1895-1965). São Paulo: Nobel; FUPAM.

Mendonça, E. M. S. (2001). Transferência de interesse no percurso da verticalização de construções em Vitória (ES) (Tese de doutorado). Universidade de São Paulo, São Paulo.

Mendonça, E. M. S., Freitas, J. F. B., Campos, M. M., Prado, M. M., \& Almeida, R. H. (2009). Cidade prospectiva: o projeto de Saturnino de Brito para Vitória. São Paulo: Annablume.

Muniz, M. I. P. (1990). Arquitetura rural do século XIX no Espírito Santo. Vitória: Universidade Federal do Espírito Santo.

Oliveira, V. (2016). Urban morphology: an introduction to the study of the physical form of cities. Londres: Springer.

Panerai, P. R., Castex, J., \& Depaule, J. C. (1986). Formas urbanas: de la manzana al bloque. Barcelona: Editorial Gustavo Gili.

Pereira Costa, S. A. (2007). O estudo da forma urbana no Brasil. Revista Eletrônica Vitruvius, 8.

Pereira Costa, S. A., \& Gimmler, M. M., No. (2015). Fundamentos de morfologia urbana. Belo Horizonte: C/Arte.

Pereira Costa, S. A., \& Teixeira, M. C. V. (2014). The study of urban form in Brazil. Urban Morphology, 18, $119-127$.

Rede Lusófona de Morfologia Urbana. (2017). Anais eletrônicos da Conferência da Rede Lusófona de Morfologia Urbana. Vitória: Universidade Federal do Espírito Santo.

Reis, N. G. (1968). Contribuição ao estudo da evolução urbana do Brasil (1500-1720) (1. ed.). São Paulo: Pioneira. Reis, N. G. (1970). Quadro da arquitetura no Brasil (1. ed.). São Paulo: Perspectiva.

Rezende, V. (2012). Urbanismo na Era Vargas: a transformação das cidades brasileiras. Niterói: UFF; Intertexto.

Rocha, H. C., \& Morandi, A. M. (1991). Cafeicultura \& grande indústria: a transição no Espírito Santo 1955-1985. Vitória: Fundação Ceciliano Abel de Almeida.

Santos, C. N. F. (1981). Quando a rua vira casa: a apropriação de espaços de uso coletivo em um centro de bairro. Rio de Janeiro: FINEP/IBAM, Projeto.

Santos, C. N. F. (1988). A cidade como um jogo de cartas. São Paulo: Projeto Editores Associados.

Santos, S. M. M., Gonçalves, W. R., \& Rodrigues, A. C. (1993). Os conjuntos habitacionais do BNH da aglomeração de Vitória: sua inserção no espaço urbano da capital (reconhecimento da situação atual dos conjuntos). Vitória: Departamento de Arquitetura e Urbanismo, Universidade Federal do Espírito Santo.

Turkienicz, B. (Ed.). (1984). Desenho urbano. São Paulo: Projeto Editores Associados.

Whitehand, J. (2008). Fourteenth International Seminar on Urban Form, Ouro Preto, Brazil, 28-31 August 2007. Journal Urban Morphology, 12.1.

Editores convidados: Vitor Oliveira (Universidade do Porto, Portugal) e Bruno Zaitter (PUCPR, Brasil)

Recebido: Set. 29, 2019

Aprovado: Mar. 22, 2020 